\title{
Foot and ankle insufficiency fractures in rheumatoid arthritis
}

\begin{abstract}
Objectives: To evaluate causes of foot and ankle insufficiency fractures in patients with rheumatoid arthritis. To conduct a literature review of low dose methotrexate induced osteopathy.

Case series: Three patients with rheumatoid arthritis who sustained foot and ankle insufficiency fractures which were only detected on MRI. All three patients were on biologic treatment and methotrexate for RA, and two had evidence of hind-foot deformity. All had evidence of osteoporosis on bone density scan, and two were already on intravenous zolendronic acid.

Conclusion: Insufficiency fractures occur in approximately $1 \%$ of patients with rheumatoid arthritis. ${ }^{1}$ Contributing factors include chronic inflammation; skeletal deformities; biomechanical stresses; use of glucocorticoids; and osteoporosis. An additional pathophysiological mechanism may be low-dose methotrexate induced osteopathy. However, there is currently insufficient evidence to conclude this.
\end{abstract}

Keywords: rheumatoid arthritis, insufficiency fractures, methotrexate osteopathy, osteoporosis
Volume 3 Issue 3 - 2015

\author{
Jeanette Trickey, Nick Barkham \\ Rheumatology Department, New Cross Hospital, United \\ Kingdom
}

Correspondence: Jeanette Trickey, Rheumatology Registrar, Rheumatology Department, New Cross Hospital, Wolverhampton Road, Wolverhampton WVI0 0QP, United Kingdom,Tel 1902307999, Email jeanettetrickey@hotmail.com

Received: July 25, 2015 | Published: September 4, 2015
Abbreviations: RA, rheumatoid arthritis; MRI, magnetic resonance imaging; CT, computerised tomography; XR, X-ray; PTH, parathyroid hormone; DEXA, dual energy X-Ray absorptiometry; NOF, neck of femur; L2-L4, second to fourth lumbar vertebrae; A\&E, accident and emergency department; MTP, meta tarso phalangeal

\section{Introduction}

Foot and ankle problems are a common complaint in patients with rheumatoid arthritis, with a prevalence estimated at $80-90 \% .^{2-5}$ This case series describes three patients whom have rheumatoid arthritis. They each had multiple foot and ankle insufficiency fractures which were not detected on X-ray imaging, but were later diagnosed on MRI. Insufficiency fractures may be difficult to diagnose in patients with rheumatoid arthritis. Presentation of an acutely painful ankle joint may be wrongly presumed to be synovitis. This may lead to a delay in diagnosis of the fracture. In one study, the delay was an average of 31 days. $^{6}$ Patients may receive intra-articular steroid injection for a joint thought to be inflamed, but was actually fractured. Insufficiency fractures in patients with rheumatoid arthritis may occur due to the chronic inflammatory nature of the disease itself. Prolonged inflammation increases the risk of structural changes which may include peri-articular osteopaenia, bone erosions, tendinopathies, and skeletal deformities. These may place abnormal biomechanical stresses on the feet and increase predisposition to insufficiency fractures. Prolonged, repeated course of corticosteroids are often used to treat flares of inflammation in patients with rheumatoid arthritis, although significantly fewer glucorticoids are used now than historically. Glucocorticoid-induced osteoporosis is mediated via increased osteoclast-mediated bone resorption, and reduced bone formation by inhibition of osteoblast proliferation and differentiation, leading to loss of bone mass. ${ }^{7,8}$ This increases risk of fractures, with up to $50 \%$ of patients with chronic glucocorticoids use sustaining insufficiency fractures. ${ }^{9,10}$

Osteoporosis is reported to be twice as common in patients with RA, with a prevalence estimated at approximately $25 \% .{ }^{11}$
This is due to chronic inflammation causing both peri-articular and generalised osteoporosis, chronic corticosteroid use, and disability imparted from the disease may reduce weight-bearing exercise. ${ }^{12}$ Fractures and delayed bone healing can occur in children on high doses of methotrexate used as chemotherapy for haematological malignancy. ${ }^{13,14}$ There is some thought that methotrexate at the low doses used to treat chronic inflammatory disorders such as RA may cause insufficiency fractures. ${ }^{15}$

\section{Case presentations}

\section{Case I}

A 76 year old gentleman with seropositive rheumatoid arthritis was diagnosed in 2008. His past medical history included interstitial lung disease, osteoporosis, hypovitaminosis $\mathrm{D}$, gout, skin psoriasis, previous endocarditis, and herpetic keratitis. His prescribed RA treatment was rituximab and oral methotrexate 20mg. In May 2014 he was still experiencing pain after his rituximab infusion, particularly in both ankles. XR imaging was unremarkable. Both ankles were injected with depomedrone, but this was ineffective. Ultrasound showed plano-valgus deformity of the left foot, and referral to foot/ ankle surgeon was advised. A MRI in July and showed fractures of the distal tibia, fibula and fifth metatarsal. It also showed hind foot valgus with associated talocalcaneal lateral hind foot impingement. The patient was reviewed by an orthopaedist, but not immobilised in plaster because the fractures were thought to be at least 8 weeks old (Figure 1-4).

The patient presented to A\&E in September 2014 with acute right hip pain, without a history of trauma. No fracture was seen on XR so patient was discharged home. An MRI was requested by his rheumatology consultant. This showed a non-displaced insufficiency fracture of the right femoral neck and an insufficiency fracture of the posterior aspect of the right acetabulum. The patient was immediately sent to the hospital for dynamic hip screw fixation (Figure $5 \& 6$ ) (Table 1). 


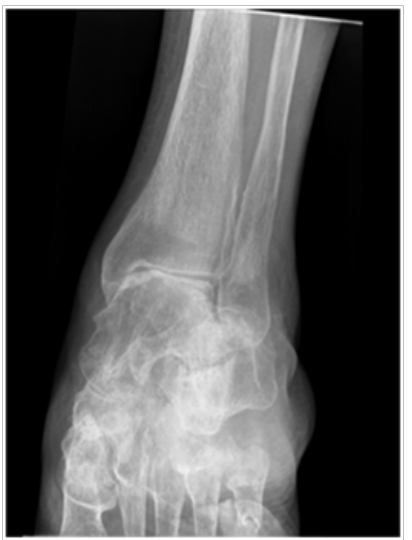

Figure I Case I XR AP view left ankle.

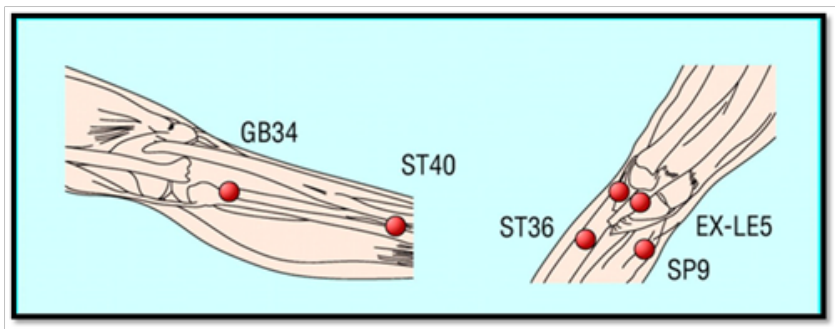

Figure 2 Case I MRI sagittal view left ankle. Fractured distal tibia.

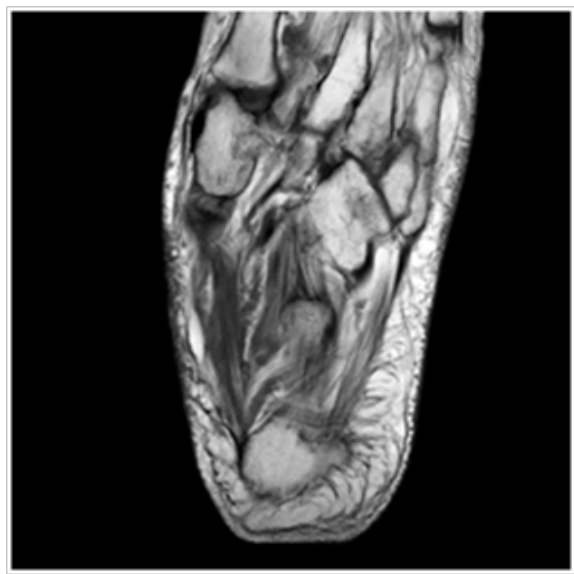

Figure 3 Case I MRI transverse view left foot. Fractured $5^{\text {th }}$ metatarsal.

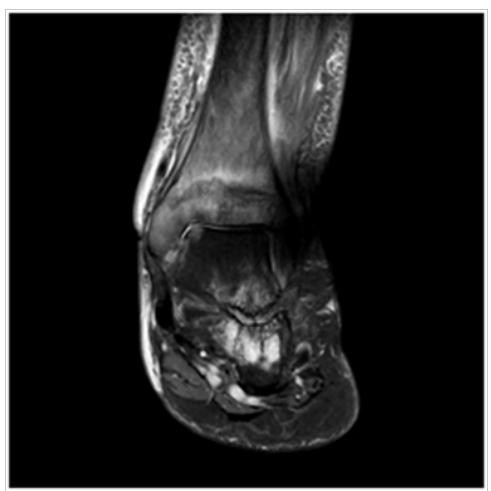

Figure 4 Case I MRI coronal view left foot and ankle. Talocalcalcaneal impingement.

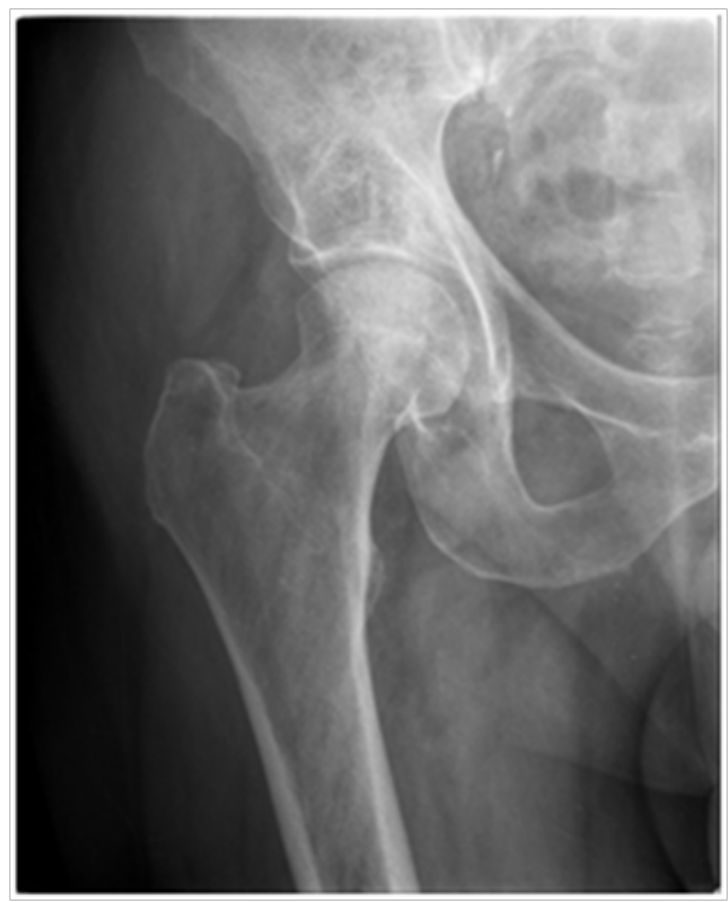

Figure 5 Case I XR AP view right hip.

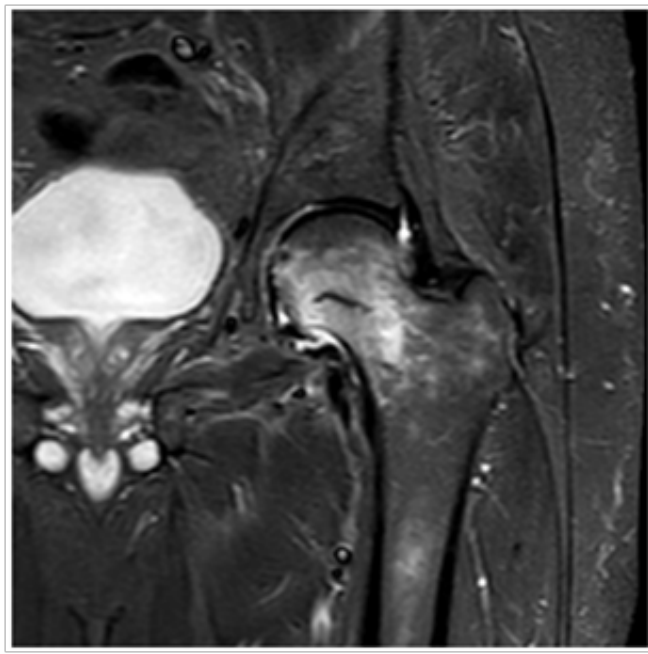

Figure 6 Case I MRI coronal view right hip. Undisplaced fracture right femoral neck.

\section{Case 2}

A 66 year old man with seropositive rheumatoid arthritis was diagnosed in 2009. His co-morbidities included emphysema, atrial fibrillation (on warfarin), and chronic haematuria. His medications included etanercept and methotrexate $20 \mathrm{mg}$. This patient had right ankle pain for 5 years, but it was worse in December 2013, so an XR was taken which appeared normal. An ultrasound guided intraarticular steroid injection was performed in February 2014. This did not alleviate the pain, so a MRI was requested. It which showed nondisplaced insufficiency fractures of the cuboid and talar neck, which appeared to be healing. There was also pes planus with lateral hind foot talocalcaneal impingement. He was reviewed by orthopaedics and supplied with a Jura-boot with medial arch support (Figure 7-10) (Table 2). 


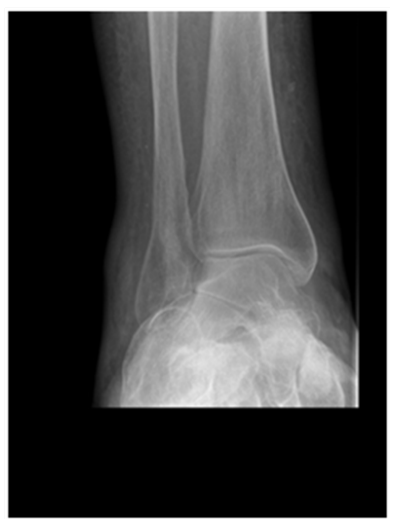

Figure 7 Case 2 XR AP view right ankle.

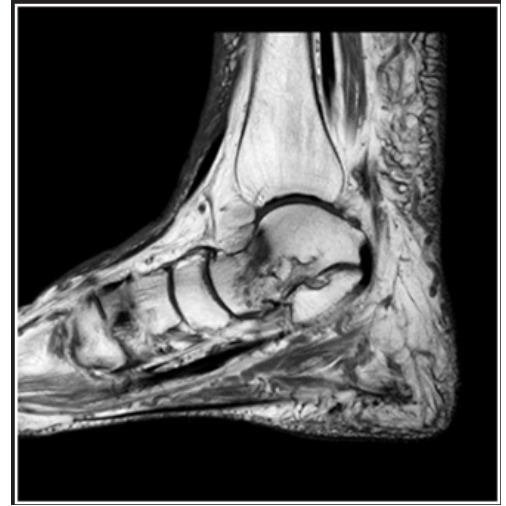

Figure 8 Case 2 MRI sagittal view right ankle. Old healing talar neck fracture.

Table I Patient demographics

\begin{tabular}{llllll}
\hline Case No & Age & Gender & $\begin{array}{l}\text { Years since RA } \\
\text { diagnosis }\end{array}$ & RA treatment & \multicolumn{2}{c}{$\begin{array}{l}\text { Duration of treatment Duration of ankle pain } \\
\text { (years) } \\
\text { (years) }\end{array}$} \\
\hline I & 76 & M & 6 & Rituximab methotrexate & ? \\
2 & 66 & M & 5 & $\begin{array}{l}\text { Etanercept } \\
\text { methotrexate }\end{array}$ & $?$ \\
3 & 63 & F & 17 & $\begin{array}{l}\text { Etanercept } \\
\text { methotrexate }\end{array}$ & ? \\
\hline
\end{tabular}

RA, rheumatoid arthritis

Table 2 Details of fractures sustained by the patients

\begin{tabular}{|c|c|c|c|c|c|}
\hline Case No & Location & Stress fractures & Hindfoot deformity & Hip fracture & $\begin{array}{l}\text { Other fragility } \\
\text { fractures }\end{array}$ \\
\hline I & Left ankle & Distal tibia, fibula and 5th metatarsal & $\begin{array}{l}\text { Hindfoot valgus, talocalcaneal } \\
\text { lateral Hindfoot impingement }\end{array}$ & Yes & T9 NOF \\
\hline 2 & Right ankle & $\begin{array}{l}\text { Old and healing talar neck. New non- } \\
\text { displaced lateral cuboid fracture }\end{array}$ & $\begin{array}{l}\text { Pes planus with lateral Hindfoot } \\
\text { talocalcaneal impingement }\end{array}$ & No & None \\
\hline 3 & $\begin{array}{l}\text { Right and left } \\
\text { ankle }\end{array}$ & $\begin{array}{l}\text { Left: distal tibia, calcaneus, cuboid, } \\
\text { cuneiforms Right: multiple calcaneal, talar } \\
\text { dome and cuboid }\end{array}$ & None & Yes & $\begin{array}{l}\text { Colles, Ist MTP, sacral, } \\
\text { lumbar vertebrae, NOF }\end{array}$ \\
\hline
\end{tabular}

NOF, neck of femur; MTP, metatarsophalangeal joint

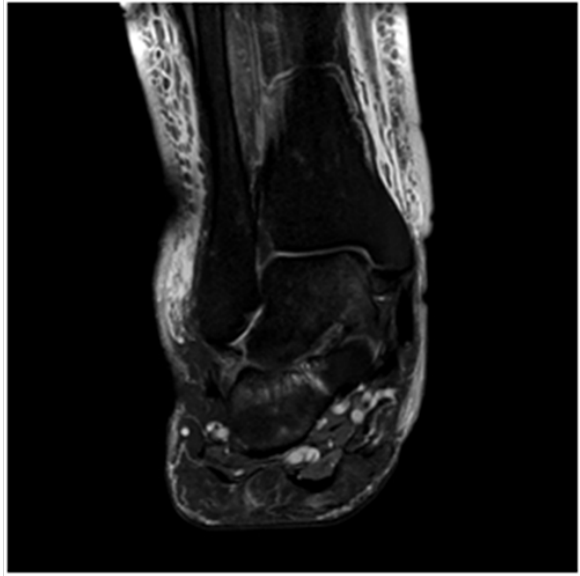

Figure 9 Case 2 MRI coronal view right ankle. Talocalcaneal impingement.

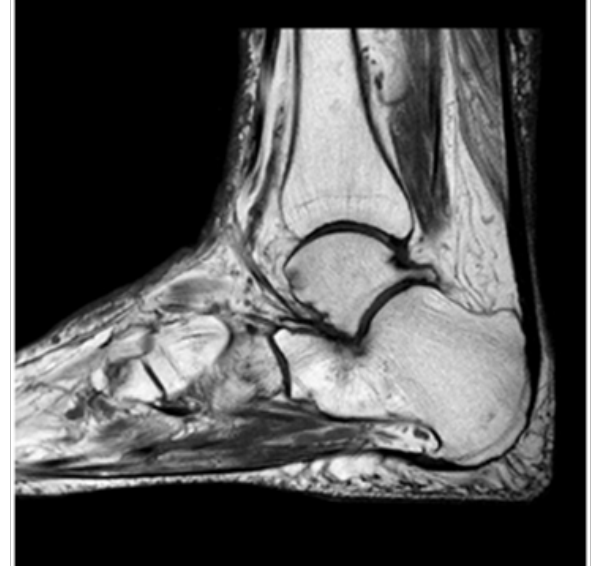

Figure 10 Case 2 MRI sagital view right ankle. New non-displaced lateral cuboid fracture. 


\section{Case 3}

A 63 year old female patient with long history of seronegative rheumatoid arthritis was treated with etanercept and methotrexate. She had a left calcaneal insufficiency fracture detected on CT in 2010 and was treated for osteoporosis with zolendronic acid. She developed further multiple insufficiency fractures of both feet, with a MRI in January 2012 showing multiple calcaneal fractures, talar dome, and cuboid fractures in the right foot with posterior tibial tenosynovitis. The left foot had distal tibia, calcaneus, cuboid, and cuneiforms insufficiency fractures. She was switched from zolendronate to teriparetide but developed an obstructed kidney due to renal calculi so this medication was stopped. The patient had a fall in January 2013, sustaining a Colles fracture and fractured first metatarsal. A further fall in June 2014 caused a left fractured neck of femur, which was fixed with dynamic hip screw. A CT lumbar spine showed a chronic sacral insufficiency fracture and marked generalised osteoporosis. She has been recommended for zolendronic acid therapy (Figure 1113) (Table 3).

Table 3 Blood results,DEXA reports and duration of bisphosphonate treatment

\begin{tabular}{|c|c|c|c|c|c|c|}
\hline Case No & $\begin{array}{l}\text { Adjusted } \\
\text { calcium } \\
(\mathrm{mmol} / \mathrm{l})\end{array}$ & $\begin{array}{l}\text { Vitamin D } \\
\text { (nmol/l) }\end{array}$ & $\begin{array}{l}\text { PTH } \\
(\mathrm{pmol} / \mathrm{l})\end{array}$ & $\begin{array}{l}\text { Documented oral } \\
\text { steroid treatment }\end{array}$ & $\begin{array}{l}\text { DEXA } \\
\text { T scores } \\
\text { (year performed) }\end{array}$ & $\begin{array}{l}\text { Osteoporosis treatment } \\
\text { (total use) }\end{array}$ \\
\hline Case I & 2.28 & 56.5 & 10.01 & none & $\begin{array}{l}\text { L2-4: }-2 . \text { I } \\
\text { L4: }-2.9 \\
\text { NOF: }-2.07 \\
\text { total hip: }-3 \\
(20 \text { I } 4)\end{array}$ & $\begin{array}{l}\text { Zolendronic acid } \\
\text { (2 years) }\end{array}$ \\
\hline Case 2 & 2.34 & 40.2 & 6.82 & $\begin{array}{l}2 \text { week course of } \\
\text { prednisolone } 25 \mathrm{mg} \text { in } 2009\end{array}$ & $\begin{array}{l}\text { L2-4: - I.9 } \\
\text { L2: }-2.6 \\
\text { NOF: }-1.5 \\
(2014)\end{array}$ & $\begin{array}{l}\text { Alendronic acid } \\
(<1 \text { years })\end{array}$ \\
\hline Case 3 & 2.22 & 87.2 & 4.33 & none & $\begin{array}{l}\text { L2-L4:-0.79 } \\
\text { NOF:-3.06 } \\
(2012)\end{array}$ & $\begin{array}{l}\text { Zolendronic acid } \\
\text { ( } 2 \text { years) }\end{array}$ \\
\hline
\end{tabular}

DEXA, dual energy X-Ray absorptiometry; NOF, neck of femur; L2-L4, second to fourth lumbar vertebrae

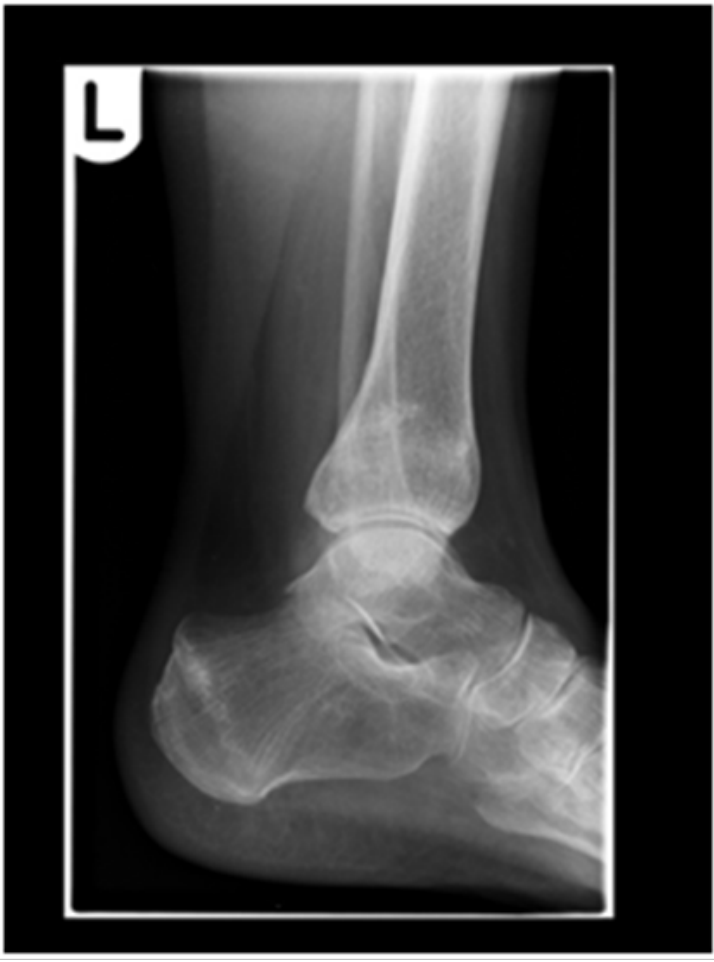

Figure I I Case 3 XR lateral view left ankle.

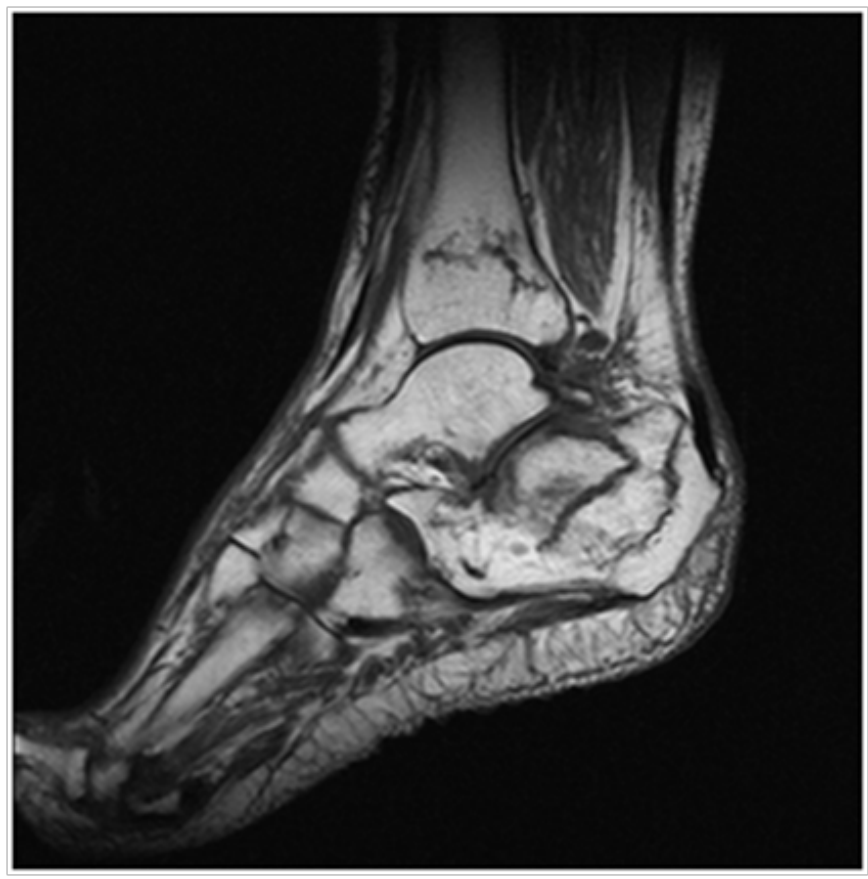

Figure 12 Case 3 MRI sagital view left ankle. Distal tibia and calcaneum fractures. 


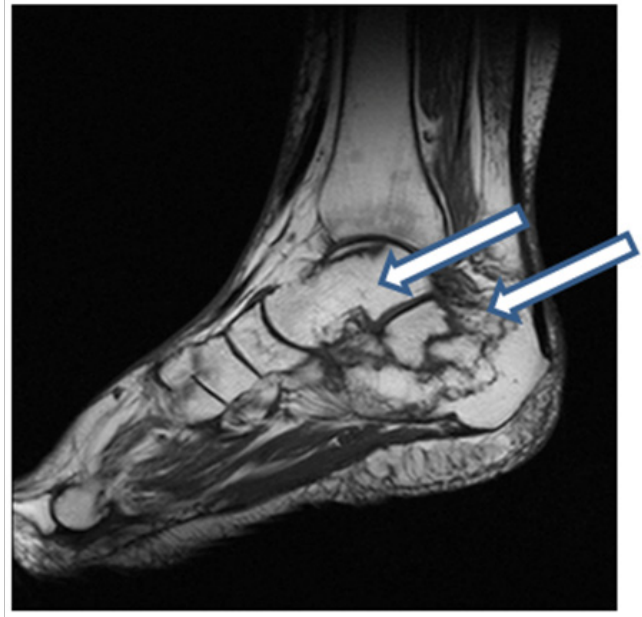

Figure I 3 Case 3 MRI sagital view right ankle. Calcaneum and talar fractures.

\section{Discussion}

The three patients in this case series demonstrated multitude of risk factors for insufficiency fractures. All three were on biologic treatment for RA, indicating that they had aggressive disease progression. Foot problems are often under diagnosed and under treated in patients with rheumatoid arthritis. This may be due to length of time taken to examine feet in clinics, so this area may be omitted from attention, and the exclusion of synovitis in the feet from DAS 28 scoring. ${ }^{16}$ Synovitis in feet and ankles can cause peri-articular osteoporosis, and bone and tendon damage that alters the biomechanics of the feet. Hindfoot deformity is common in RA, in particular pesplanovalgus deformity prevalence increases with duration of disease and occurs in up to $50 \%$ of patients with rheumatoid arthritis. It is associated with tenosynovitis or tears of posterior tibialis tendon. ${ }^{5}$ Two cases in this study had hind foot deformities that may have contributed to the insufficiency fractures. Physical inactivity may result from disease activity in RA. This may reduce sunlight exposure, and therefore reduce vitamin D levels. Low levels of weight-bearing exercises are a risk factor for osteoporosis. ${ }^{17}$ These can contribute to low bone mineral density, and therefore, insufficiency fractures.

Osteoporosis, likely has played a large part in the pathophysiology of the insufficiency fractures in these patients. All three patients had evidence of low bone mineral density. The DEXA results in Table 3 show that all three patients had a T-score less than -2.5 (although in case 2 this was only at one lumbar vertebral level). Two of the patients had a prior diagnosis of osteoporosis and already had two treatment doses of zolendronic acid. Atypical stress fractures of the proximal femoral shaft have been reported in patients on long term bisphosphonate therapy. ${ }^{15}$ However, neither of our patients had been on this treatment for sufficient time for the fractures to be attributed to prolonged bisphosphonate use. Osteomalacia is another cause of low bone mineral density which can cause insufficiency fractures. None of the patients in this series were in the severe deficiency range, but one patient had inadequate levels and another had a level just over $50 \mathrm{mmol}$, which is the agreed level as being sufficient for $50 \%$ of the population. ${ }^{18}$

Glucocorticoid-induced osteoporosis is a mechanism for insufficiency fracture. High doses and prolonged courses of glucocorticoids are a predictor, and the risk of insufficiency fractures is increased before changes in bone mineral density are seen. ${ }^{19}$ However no patients in this case series had received multiple repeated courses of prednisolone (Table 1). Methotrexate-induced osteopathy has been described as an uncommon complication of long term high dose methotrexate use for maintenance chemotherapy treatment of malignancies in children, particularly acute lymphoblastic leukaemia. It may cause bone pain, osteoporosis, and fractures, typically of the distal tibia. ${ }^{20}$ Methotrexate was found to cause increased calcium and phosphate levels in urine and faeces, suggesting that it causes increased bone turnover. ${ }^{21}$ There have since been a few studies suggesting that methotrexate in low doses used for inflammatory conditions, such as rheumatoid arthritis, can induce osteopathy. There are reports of resolution of symptoms and XR changes after withdrawing methotrexate, with delayed fracture healing with methotrexate. However, the majority of these studies were case reports or small case series. ${ }^{22,23}$ One case report of two such patients had results of iliac crest biopsies which showed osteoblast inhibition, thought to be the mechanism by which methotrexate induces osteopathy. ${ }^{15}$ However, one group has found no effects of methotrexate in vitro or in vivo in low doses in participants with rheumatoid arthritis. ${ }^{24}$ Delayed fracture healing was only seen at high doses of methotrexate ${ }^{25,26}$ and not at low doses. In some case reports attributing fractures to low dose methotrexate induced osteopathy, no mention of BMD measurement was made. ${ }^{27}$ The majority of patients had varying doses of glucocorticoids in the past and bone biopsies were performed in only a few cases. A large US and Canadian cohort study of more than 16,000 patients with RA found no significant difference in incidence of insufficiency fractures in patients taking methotrexate, biologics, or other DMARDs. ${ }^{28}$

The patients in this case series are all on methotrexate, although one patient had methotrexate omitted for several months before the occurrence of the fractures due to concurrent infection. These patients were all on biologic therapy, meaning that the withdrawal of methotrexate would be problematic. It could worsen control of disease activity, and rituximab must be prescribed with methotrexate due to NHS drug licensing. Instead of stopping methotrexate we chose to continue to treat the patients' rheumatoid arthritis and osteoporosis to prevent further fractures.

\section{Conclusion}

Insufficiency fractures may be easily missed in patients with rheumatoid arthritis, so a high index of suspicion is needed. Patients at higher risk are those with known osteoporosis, longer duration of disease, prolonged high dose glucocorticoid use, and abnormal architecture of the feet. X-ray imaging is often normal, so CT or MRI should be considered in high risk patients. Two cases in this study went on to have fractured neck of femurs after their initial foot/ ankle fractures. One year mortality after hip fracture is $20 \%$, so it is clearly important to identify and manage risk factors for fragility fracture in patients with rheumatoid arthritis. There is currently no significant evidence to conclude that low dose methotrexate induces bone fracture or delays fracture healing.

\section{Acknowledgments}

None.

\section{Conflicts of interest}

The authors declare there is no conflict of interest. 


\section{References}

1. Kay LJ, Holland TM, Platt PN. Concise report: stress fractures in rheumatoid arthritis: a case series and case-control study. Ann Rheum Dis. 2004;63(12):1690-1692.

2. Kerry RM, Holt GM, Stockley I. The foot in chronic rheumatoid arthritis: a continuing problem. The Foot. 1994;4(4):201-203.

3. Michelson J, Easley M, Wigley FM, et al. Foot and ankle problems in rheumatoid arthritis. Foot Ankle Int. 1994;15(11):608-613

4. Vainio K. The rheumatoid foot: a clinical study with pathological and roentgen logical comments. Clin Orthop Relat Res. 1991;(265):4-8.

5. Helliwell P, Woodburn J, Redmond A, et al. The foot and ankle in rheumatoid arthritis. Elsevier: Churchill Livingstone; 2007.

6. Elkayam O, Paran D, Flusser G, et al. Insufficiency fractures in rheumatic patients: misdiagnosis and underlying characteristics. Clin Exp rheumatol. 2000;18(3):369-374.

7. Gennari C, Imbimbo B. Effects of prednisone and deflazacort on vertebral bone mass. Calcif Tissue Int. 1985;37(6): 592-593.

8. Canalis E, Mazziotti G, Giustina A, et al. Glucocorticoid-induced osteoporosis: pathophysiology and therapy. Osteoporos Int. 2007;18(10):1319-1328.

9. Van Staa TP, Leufkens HG, Abenhaim L, et al. Use of oral corticosteroids and risk of fracture. Bone Miner Res. 2000;15(6):993-1000.

10. Bisphosphonates: atypical femoral fractures. Medicines and Healthcare products Regulatory Agency. 2011.

11. Hauser B, Riches PL, Wilson JF, et al. Prevalence and clinical prediction of osteoporosis in a contemporary cohort of patients with rheumatoid arthritis. Rheumatology. 2014;53(10):1759-1766.

12. Suzuki Y, Mizushima Y. Osteoporosis in rheumatoid arthritis. Osteoporosis International. 1997;7(Suppl 3):217-222.

13. Ragab AH, Frech RS, Vietti TJ. Osteoporosis fractures secondary to methotrexate therapy of acute leukaemia in remission. Cancer. 1970;25(3):580-585.

14. Stanisavljevic S, Babcock AL. Fractures in children treated with methotrexate for leukaemia. Clin Orthop Rel Res. 1977;125:139-144.

15. Preston SJ, Diamond T, Scott A, et al. Methotrexate osteopathy in rheumatic disease. Ann Rheum Dis. 1993;52(8):582-585.
16. Wechalekar MD, Lester S, Proudman SM, et al. Active foot synovitis in patients with rheumatoid arthritis: applying clinical criteria for disease activity and remission may result in underestimation of foot joint involvement. Arthritis Rheum. 2012;64(5):1316-1322.

17. Grimston SK, Willows ND, Hanley DA. Mechanical loading regime and its relationship to bone mineral density in children. Med Sci Sports Exerc. 1993;25(11):1203-1210.

18. Francis R, Aspray T, Fraser W, et al. Vitamin D and Bone Health A Practical Clinical Guideline for Patient Management. National Osteoporosis Society Practical Guideline. 2013.

19. Warriner A, Saag KG. Prevention and treatment of bone changes associated with exposure to glucocorticoids. Curr Osteoporos Rep. 2013;11(4):341-347.

20. Schwartz AM, Leonidas JC. Methotrexate osteopathy. Skeletal Radiol. 1984;11(1):13-16.

21. Nevinny HB, Krant MJ, Moore EW. metabolic studies of the effects of methotrexate. Metabolism. 1965;14(2):135-140.

22. Zonneveld IM, Bakker WK, Dijkstra PF, et al. Methotrexate osteopathy in long-term, low-dose methotrexate treatment for psoriasis and rheumatoid arthritis. Arch Dermatol. 1996;132(2):184-187.

23. Moen M, Weir A, van Rijthoven A, et al. Medial tibial stress syndrome induced by methotrexate: a case report. 2011;26(3):258-261.

24. Minaur NJ, Kounali D, Vedi S, et al. Methotrexate in the treatmen of rheumatoid arthritis II In vivo effects on bone mineral density. Rheumatology. 2002;41(7):741-749.

25. Satoh K, Mark H, Zachrisson P, et al. Effect of methotrexate on fracture healing. Fukushima J Med Sci. 2011;57(1):11-18.

26. Cavalcanti SC, Corrêa L, Mello SB, et al. The effect of methotrexate on the bone healing of mandibular condylar process fracture: an experimental study in rats. Craniomaxillofac Surg. 2014;42(7):1133-1139.

27. Alonso-Bartolome P, Martinez-Taboada VM, Canga A, et al. Media tibial stress syndrome due to methotrexate osteopathy. Ann Rheum Dis. 2006;65(6):832-833.

28. Kim SK, Schneeweiss S, Liu J, et al. Effects of disease-modifying anti rheumatic drugs on non-vertebral fracture risk in rheumatoid arthritis: a population-based cohort study. J Bone Miner Res. 2012;27(4):789-796. 